\title{
RENAL EXPRESSION OF ENDOTHELIAL NITRIC OXIDE SYNTHASE AFTER CPB IN RAT
}

Francoise Briet PhD, Gregory M. T. Hare MD PhD, Katherine R. Blight MD, Zhilan Wang MSc, Carla Coackley, Alana M. Harrington, Malcolm Robb PhD, Duncan J. Stewart MD and C. David Mazer MD

Department of Anesthesia and Division of Cardiology, University of Toronto, St. Michael's Hospital, Toronto, Ontario, M5B 1W8

\section{INTRODUCTION}

Acute renal failure is one of the major complications of cardiac surgery and CPB, occurring in approximately $5 \%$ of patients ${ }^{1}$. Postoperative renal dysfunction increases the risk of mortality more than 20 fold, and triples the hospitalization costs. Although the mechanism is not clear, lower hematocrit and urine pO2 level are predictive of renal injury, suggesting that reduced oxygen delivery may be important. Hypoxia is known to cause changes in expression of a number of genes, including NOS (nitric oxide synthase) and VEGF (vascular endothelial growth factor $)^{2}$. The purpose of this study was to determine if CPB results in hypoxic gene expression in the kidney.

\section{METHODS}

After ACC approval, Sprague-Dawley rats were anesthetised with ketamine and maintained with isoflurane, fentanyl, midazolam and cis-atracurium. Rats underwent either normothermic CPB with a neonatal membrane oxygenator for 1 hour or no $\mathrm{CPB}$, which was equivalent to "shamoperated" negative controls ( $\mathrm{n}=7$ per group). On the following postoperative day, animals were sacrificed and total RNA was extracted from the renal cortex and medulla. Analysis of endothelial (e)NOS, VEGF and GAPDH mRNA levels was performed using quantitative real time PCR technique. Gene expression results for CPB were compared to sham group in both tissues using unpaired t-tests.

\section{RESULTS}

There were no significant differences in physiological variables (hemoglobin concentration, mean arterial pressure, rectal temperature and oxygen saturation) between CPB and sham groups. Significant upregulation of eNOS occurred in the CPB group as compared to the sham-operated rats in renal medulla (sham $1.7+/-0.4$, CPB $3.1+/-0.6$ fg template, $p<0.03$ ). Gene expression in the renal cortex was comparable in both groups. There were no significant differences in VEGF and GAPDH expression between CPB and sham animals in both tissues.

\section{DISCUSSION}

$\mathrm{CPB}$ is associated with increased renal medullary expression of eNOS in this model. eNOS mediated NO production is involved in the regulation of the glomerular and medullary

microcirculation $^{3}$, and may contribute to the renal protective effect of ischemic preconditioning ${ }^{4}$. A significant increase of eNOS may have a local vasodilator effect, favouring oxygenation and could be protective against renal injury after $\mathrm{CPB}$.

\section{REFERENCES}

1. JN 1999; 12 (suppl 2): S142-S151.

2. Am J Physiol 2003; 284: R628-R638.

3. Ann Med 1995; 27: 407-420.

4. J Pharmacol Exp Ther. 2005 312(1):153-9 